\title{
Developing robust field survey protocols in landscape ecology: a case study on birds, plants and butterflies
}

\author{
Jacqueline Loos • Jan Hanspach • Henrik von Wehrden • \\ Monica Beldean · Cosmin Ioan Moga $\cdot$ Joern Fischer
}

Received: 22 December 2013/Revised: 5 August 2014/Accepted: 18 August 2014/

Published online: 28 August 2014

(C) The Author(s) 2014. This article is published with open access at Springerlink.com

\begin{abstract}
Sustainable land management requires scientists to provide reliable data on diversity distribution patterns. Resource restrictions limit the affordable sampling effort, both with respect to number of survey sites and amount of effort per site. We compared different levels of survey effort in a case study in Central Romania, varying the number of repeats per site and number of survey sites. Target taxa were plants, birds and butterflies. For plants, we surveyed three $10 \mathrm{~m}^{2}$ plots and ten plots of $1 \mathrm{~m}^{2}$ at each site. For birds, we used point counts and for butterflies Pollard walks, in both cases with four repeats. We fitted hierarchical community models to estimate true species richness per site. Estimates of true species richness per site strongly correlated with observed species richness. However, hierarchical community models yielded unrealistically high estimates of true species richness per site, hence we used observed richness for further analyses. For each species group, we compared diversity indices from subsets of the dataset with the full dataset. Findings obtained with a reduced survey effort reflected well those obtained with full effort. Moreover, we conducted a power analysis to assess how the number of survey sites affected the minimum detectable effect of landscape heterogeneity on species richness, and found there was an exponential decrease in the minimum detectable effect with increasing number of sites. In combination, our findings suggest that assessing broad
\end{abstract}

Communicated by Astrid van Teeffelen.

J. Loos $(\bowtie) \cdot$ J. Hanspach $\cdot$ H. von Wehrden · J. Fischer

Faculty of Sustainability, Leuphana University, Scharnhorststrasse 1, 21335 Lüneburg, Germany

e-mail: loos@leuphana.de

H. von Wehrden

Center for Methods, Leuphana University, Scharnhorststrasse 1, 21335 Lüneburg, Germany

M. Beldean

Faculty of Biology and Geology, Babeş-Bolyai University Cluj-Napoca, Strada Republicii 42,

400015 Cluj-Napoca, Romania

C. I. Moga

Educational-Ecological Association Ecotransilvania, Strada Gării 5, 545400 Sighişoara, Romania 
diversity patterns in abundant and readily detectable organisms may be possible with relatively low survey effort per site. Our study demonstrates the utility of conducting pilot studies prior to designing large-scale studies on diversity distribution patterns.

Keywords Detectability - Hierarchical model $\cdot$ Landscape heterogeneity $\cdot$ Species distribution $\cdot$ Species richness $\cdot$ Statistical power $\cdot$ Study design

\section{Introduction}

Human land use is a major driver of biodiversity loss (Sala et al. 2000). However, not all types of land use are equally threatening to biodiversity, and some strategies of land management can effectively sustain substantial biodiversity (Tscharntke et al. 2005; Rands et al. 2010; Mouysset et al. 2012). One of the prerequisites for appropriate land management is a thorough understanding of species distribution patterns, often across entire landscapes or regions (Gaston 2000; Dover et al. 2011). Quantifying distribution patterns, in turn, demands robust and reproducible field survey protocols for a range of different species (Lobo et al. 2010). Important variables in this context include patterns of local species richness (Yoccoz et al. 2001), species turnover (Tylianakis et al. 2005; Kessler et al. 2009), and species composition (Klimek et al. 2007).

Research projects investigating biodiversity distribution patterns are usually constrained by limited resources including money, personnel and time (Field et al. 2005; Baasch et al. 2010). These constraints pose limits on the affordable sampling effort, both with respect to the number of sites surveyed and the amount of effort per site. Scientists may opt for applying substantial effort at relatively few sites or for surveying a large number of sites with reduced effort. Collecting data in ways that allow the detection process to be modelled is often considered important to minimize the impact of false absences, especially in the case of animals (MacKenzie et al. 2002; Lahoz-Monfort et al. 2013; Stauffer et al. 2002). This is often done by repeatedly surveying a given site, but other methods are possible such as recording times to detection (Guillera-Arroita et al. 2011).

To collect reliable data using limited resources, ecologists thus face a trade-off between the number of survey sites and the number of repeated surveys at each sample site (Bried et al. 2011; Reed et al. 2011; Reynolds et al. 2011; Bailey et al. 2007; Suarez-Seoane et al. 2002; Guillera-Arroita and Lahoz-Monfort 2012; Guillera-Arroita et al. 2010). One tool to investigate tolerable information loss when survey effort is reduced is to evaluate the statistical power of the different survey designs (Field et al. 2005; Legg and Nagy 2006; Bailey et al. 2007; Vellend et al. 2008; Guillera-Arroita and Lahoz-Monfort 2012; Sewell et al. 2012). Power analysis calculates the size of an effect that is detectable with a certain level of confidence and significance for a given design. Power increases as more effort is spent per site (given that detectability increases), as well as when the number of sites is increased.

In this study, we examined how estimated species diversity patterns changed with varying survey intensity and a varying number of survey sites. We focused on a case study in Central Romania, a region that is characterized by low-intensity land use practices (Baur et al. 2006; Fischer et al. 2012; Kuemmerle et al. 2008), which have created a heterogeneous landscape that supports high biodiversity (Rakosy 2005; Page et al. 2012; Fischer et al. 2012). However, biodiversity in the region is threatened by a series of complex socio- 
economic changes, including potential changes in land use. These changes include land abandonment and agricultural intensification (Bouma et al. 1998; Stoate et al. 2009; Akeroyd and Page 2011), both of which have been observed to negatively affect biodiversity elsewhere in Europe (Suarez-Seoane et al. 2002; Verhulst et al. 2004).

We conducted surveys for three taxonomic groups, namely plants, birds and butterflies, which are particularly diverse in Romania compared to most other parts of Europe (Akeroyd 2006). Our study served as a pilot to design subsequent large-scale surveys for these groups. First, we investigated the effect of increasing survey intensity on diversity patterns, as represented by species richness, turnover and composition. Second, we calculated the statistical power of alternative plausible designs varying in survey intensity and number of survey sites for a specific relationship, namely the relationship between landscape heterogeneity, represented by the variability in land covers within a specific area, and species richness.

\section{Methods}

Study area

The study was conducted within a $50 \mathrm{~km}$ radius of Sighişoara, southern Transylvania, Romania $\left(45^{\circ} 45^{\prime} 48 \mathrm{~N}-46^{\circ} 40^{\prime} 17 \mathrm{~N} ; 24^{\circ} 8^{\prime} 7 \mathrm{E}-25^{\circ} 26^{\prime} 40 \mathrm{E}\right)$. The landscape is undulating, with altitudes between 266 and $1,095 \mathrm{~m}$ above sea level. It is characterized by a heterogeneous and fine-grained mosaic of different land uses, including substantial amounts of seminatural vegetation. Approximately $37 \%$ of land is arable, $24 \%$ is grassland (pastures and meadows), and $28 \%$ is covered by forests. We initially identified a large number of potential survey points by comprehensively walking the land around each of five villages, covering all major land covers around each village in the process. Based on this initial reconnaissance survey, we randomly selected 35 points as survey sites, located in arable land $(n=17)$, grassland $(n=13)$ and forest $(n=5)$. Each survey site was defined as a circle measuring one hectare. Sites were located with a minimum distance of $200 \mathrm{~m}$ from each other and a maximum distance of $6,339 \mathrm{~m}$ within one village.

Field surveys

Plants

We used two different survey approaches to quantify plant species richness and composition. First, we used a 'classical' approach at all 35 survey sites from 1st May to 30th May 2011. We established three $30 \times 30 \mathrm{~m}$ plots in each 1 ha site. Within each $30 \times 30 \mathrm{~m}$ plot, we selected one representative $3.16 \times 3.16 \mathrm{~m}$ subplot, in which we recorded the presence and percentage cover of all vascular plant species (Fig. 1). Second, we used a 'cartwheel' approach to resample plants in a subset of 19 (n: arable land $=6$, grassland $=8$, forest $=5$ ) of the 35 survey sites from 1st June to 15th July 2011. We decided to only resample sites that have remained largely unchanged since the first sampling round, i.e. in which no harvesting or mowing have occurred. In each 1 ha site, we distributed ten plots of $1 \times 1 \mathrm{~m}$ at a random distance from the middle point, every 36 degrees. We alternated the random distances so that five plots were distributed within $40 \mathrm{~m}$ of the center (the inner $0.5 \mathrm{ha}$ ) and five were located between 40 and $56 \mathrm{~m}$ from the center (the outer 0.5 ha; Fig. 1). We then recorded the presence and percentage cover of all vascular plant 
Fig. 1 Illustration of the sampling scheme for a bird surveys; b plants surveys: classical approach; c plant surveys: cartwheel approach; and d butterfly surveys
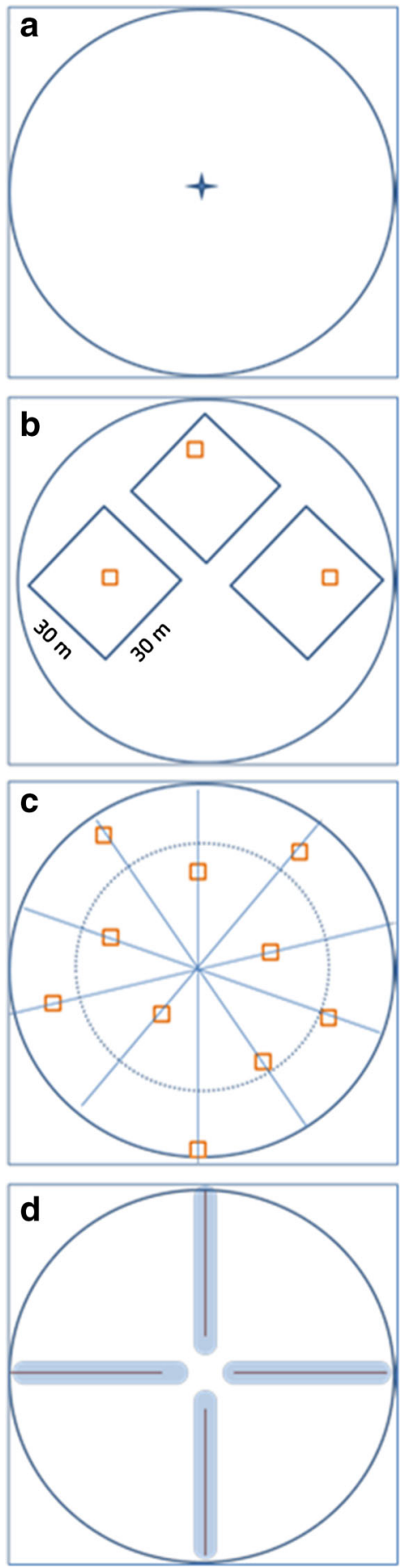
species in each plot. Phenological changes over the two survey periods were minor, and did not cause systematic differences in the species detected.

\section{Birds}

Birds were surveyed at all 35 sites using 20 min point counts (Bibby 2000) between 1st May and 8th June 2011, on those days without rain or strong wind (Fig. 1). At each site, four surveys were conducted between 05:30 and 11:00 AM, noting the presence of singing males. We controlled for temporal bias by rotating the site order, except for the forest sites which were always surveyed first in the morning to maximize detections.

\section{Butterflies}

Butterflies were surveyed four times at 26 sites (12 sites in arable land, 12 grassland sites and two forest sites) by walking Standard Pollard Transects (Pollard and Yates 1993) between 1st June and 15th July 2011. At each site, we sampled four transects with a length of $50 \mathrm{~m}$ to the east, south, north and west from the center (i.e. total of $200 \mathrm{~m}$ per site; Fig. 1). Surveys were conducted at a pace of $10 \mathrm{~m}$ per minute when weather conditions were appropriate (no rain, $<90 \%$ cloud cover, $>17{ }^{\circ} \mathrm{C}$, no strong wind). All butterflies within $2.5 \mathrm{~m}$ on either side of a given transect were caught with a butterfly net, identified and released. For identification, we used pan-European and eastern European guides (Tshikolovets 2003; Lafranchis 2004).

Analysis

\section{Estimation of species richness and composition}

We calculated species richness as the sum of all recorded species per taxonomic group over all plots or repeats in a given site. We calculated Whittaker's $\beta$-diversity index as a measure of species turnover among the sites and repeats in our dataset (Whittaker 1960; Anderson et al. 2011).

To compare plant survey methods, we correlated the species richness obtained by the two approaches using Spearman Rank correlation. In subsequent analyses, we considered data obtained by the cartwheel approach, since the randomized placement of plots within a site was more representative for the variation within a site.

We applied hierarchical community models to estimate true species richness at each site. Hierarchical community models can be used to estimate true species richness under consideration of the species specific detectability (Dorazio and Royle 2005; Dorazio et al. 2006). We considered the detectability of each species as a function of survey date and set the number of augmented species to $2 / 3$ of the observed richness (Kéry and Royle 2009; Zipkin et al. 2009). Species augmentation accounts for the possibility that some species remained unobserved in a survey with imperfect detection. A community model with species augmentation will estimate the occupancy of unobserved species as a function of estimated detection probability of the observed species. The occupancy of observed and unobserved species, in turn, is used to calculate true species richness. Moreover, we assumed that detectability was constant and that populations were closed, that is, population sizes were constant and were not subject to processes such as recruitment, mortality or dispersal. Estimated true species richness at the site level was highly correlated with 
observed species richness (see results). However, the estimated values of true species richness were rather high for plants and butterflies (see results). This likely over-estimation probably resulted from the small number of sites and the fact that populations were not closed (for more details see: Kéry and Schaub 2012, pp. 414-461). Based on the high correlations with observed richness, but partly unrealistically high estimates for butterflies and plants, we continued further analyses using observed species richness rather than estimated true richness values as a baseline describing the outcomes of a "full survey effort".

We described species composition using several multivariate analysis tools. To describe species composition we conducted detrended correspondence analyses (DCAs) with presence/absence data for birds, and abundance data for plants. Abundance data of butterflies was analysed using principal component analyses (PCAs). We chose these ordination methods because the length of the gradient of the first DCA axis was $>3$ for plants and birds and $<3$ for butterflies (Ter Braak and Prentice 1988).

\section{Assessment of the impact of survey effort reductions}

For a given group of species, we were interested in comparing the data from a "full survey effort" with that of a "reduced survey effort". Our full survey effort consisted of ten plots per site for plant surveys, four repeats per site for butterfly surveys, and four repeats per site for bird surveys. For each group, we considered species richness, species turnover and species composition. We treated the results of species richness and species composition resulting from the full survey effort as "observed" richness and composition, respectively. We simulated subsets of the full survey effort by randomly dropping one to seven plots (for plants) or one to three repeats (for birds and butterflies) from the dataset. Random sampling of reduced datasets was repeated 100 times for each selection, and agreement of the reduced set was compared with the full dataset. Species richness and turnover of the reduced datasets was compared to the full dataset using Spearman Rank correlations.

We then assessed how strongly species composition changes when reducing the survey effort. This was done by using Procrustes analyses, which identifies differences of the locations of objects between two ordinations. Comparisons were performed between the ordination of the reduced dataset and the full dataset and differences were quantified by calculating a correlation based on the symmetric sum of squares between the two ordinations (Peres-Neto and Jackson 2001).

\section{Power analysis of the effect of different survey designs}

Study design and data quality fundamentally influence the statistical power in the analysis of survey data. We therefore investigated the effect of different designs on the power of linear models relating species richness with environmental variables. We used a simulation approach that reflects the nature of the variability in the field data, but in which the sample size can be varied. It is then possible to test how strong the actual effect of a specific variable needs to be, for a dataset with a certain sample size to detect such an effect.

Specifically, we applied power analyses to detect effects of landscape heterogeneity on species richness. The loss of landscape heterogeneity is a key concern in Europe's agricultural landscapes (Benton et al. 2003), and is particularly relevant to our study area where low-input, small scale farming is increasingly replaces by industrialized high-input agriculture. We limited this analysis to arable sites, because this is where heterogeneity is most likely to be lost in the future due to land use intensification. We calculated 
heterogeneity as the standard deviation (SD) of the normalized difference vegetation index (NDVI) from $10 \mathrm{~m}$ monochromatic SPOT data (CCNES (2007), Distribution Spot Image SA) within each of the one hectare (arable) sites.

The methods used for the subsequent simulations are described in detail by Bolker (2008), and are summarized here for our data. During the simulation we increased the sample size from the original number of 17 sites of arable land to a hypothetical maximum of 170 sites. We generated explanatory data from a uniform distribution spanning the range of heterogeneity values observed in the original 17 sites. We also varied effect size from no effect to a strong effect, that is, from no change in species richness along the heterogeneity gradient to a change in species richness that equaled the maximum number of species that was counted in a single site ( 32 species for plants, 12 species for birds and 22 species for butterflies). This effect was converted to 200 increasingly large hypothetical slopes for a regression line (from slope $=0$ to increasingly steeper slopes). Based on a given slope, we simulated species richness for each taxonomic group. To these simulated species richness values, we added a random variation. Random variation was generated by randomly drawing values from a normal distribution with a mean of zero and a standard deviation as large as in the original species richness data (10.27 for plants, 1.93 for birds, and 5.43 for butterflies). For this purpose, we used the plant richness data from surveying seven plots, and bird and butterfly richness data from three repeated surveys.

For each dataset thus generated, we fitted a simple linear model of simulated richness on simulated heterogeneity. We repeated this process 1,000 times for each combination of number of survey sites and slope. For each combination of number of survey sites and slope, we noted how often we found a significant effect in the simulated data. Because data were simulated to be variable, sometimes the simulated effect was detected at the significance level of 0.05 , and sometimes no effect was detected despite there being one (type II error). We were interested in how the incidence of type II errors varied with the number of survey sites and effect size (slope)—both more survey sites and steeper slopes will reduce the incidence of type II errors, that is, lead to greater statistical power. For each examined taxonomic group, and for a given number of survey sites, we noted the minimum slope ("minimum detectable effect" or MDE) at which the type II error rate was $<0.2$ (i.e. power $>0.8$ ). In a last step, the MDE was expressed as the difference in the number of species between the site with the lowest and highest heterogeneity.

\section{Results}

We detected 293 vascular plant species from 35 sites with the classical approach and 310 plant species from 19 sites with the cartwheel approach. We recorded 53 bird species (35 sites) and 81 butterfly species (26 sites) (Table 1). We found the highest values for species turnover between sites for plants with the classical approach (mean \pm SD: $\beta=12.6 \pm 11.1)$ and the cartwheel approach $(\beta=8.8 \pm 5.9)$, followed by birds $(\beta=9.1 \pm 6.9)$. Butterflies showed the lowest turnover $(\beta=7.1 \pm 8.4)$.

Plant species richness from the two different sampling methods was strongly positively correlated (Pearson correlation coefficient $\mathrm{r}=0.77 \mathrm{df}=17, P<0.05$ ). Species richness differed between the two approaches most strongly within agricultural fields (Pearson correlation $\mathrm{r}=0.04$, $\mathrm{df}=5, P=0.9$; non-arable sites: $\mathrm{r}=0.92$, $\mathrm{df}=12, P<0.05$ ). Here, survey plots were selected to be within actual fields for the classical approach, while the random selection of plots in the cartwheel approach more frequently included weed and field edge vegetation. Consequently, estimates of richness were higher using the cartwheel 
Table 1 Mean species richness per site (and standard deviation) in the three land cover types surveyed

\begin{tabular}{|c|c|c|c|}
\hline & Plants & Birds & Butterflies \\
\hline Arable & $\begin{array}{l}47.4 \pm 12.2 \\
\text { Festuca pratensis } \\
\text { Taraxacum officinale } \\
\text { Stellaria media } \\
\text { Poa angustifolia } \\
\text { Elymus repens } \\
\text { Medicago sativa } \\
\text { Rhinanthus rumelicus } \\
\text { Carex hirta } \\
\text { Capsella bursa-pastoris } \\
\text { Symphytum officinale }\end{array}$ & $\begin{array}{l}6.6 \pm 3.2 \\
\text { Alauda arvensis } \\
\text { Acrocephalus palustris } \\
\text { Sylvia communis } \\
\text { Saxicola rubetra } \\
\text { Lanius collurio } \\
\text { Erithacus rubecula } \\
\text { Parus major } \\
\text { Fringilla coelebs } \\
\text { Phylloscopus collybita } \\
\text { Turdus merula }\end{array}$ & $\begin{array}{l}18.0 \pm 6.2 \\
\text { Maniola jurtina } \\
\text { Melanargia galathea } \\
\text { Plebeius argus } \\
\text { Coenonympha pamphilus } \\
\text { Polyommatus icarus } \\
\text { Thymelicus sylvestris } \\
\text { Leptidea sinapis/juvernica } \\
\text { Thymelicus lineolus } \\
\text { Everes argiades } \\
\text { Aphantopus hyperantus }\end{array}$ \\
\hline Grassland & $\begin{array}{l}61.4 \pm 13.1 \\
\text { Trifolium repens } \\
\text { Festuca rupicola } \\
\text { Achillea millefolium } \\
\text { Poa angustifolia } \\
\text { Taraxacum officinale } \\
\text { Festuca pratense } \\
\text { Anthoxanthum odoratum } \\
\text { Crataegus monogyna } \\
\text { Plantago lanceolata } \\
\text { Trifolium pratense }\end{array}$ & $\begin{array}{l}7.4 \pm 4.1 \\
\text { Acrocephalus palustris } \\
\text { Alauda arvensis } \\
\text { Sylvia communis } \\
\text { Saxicola rubetra } \\
\text { Saxicola torquata } \\
\text { Passer montanus } \\
\text { Lanius collurio } \\
\text { Motacilla flava } \\
\text { Emberiza citrinella } \\
\text { Parus palustris }\end{array}$ & $\begin{array}{l}20.0 \pm 6.1 \\
\text { Maniola jurtina } \\
\text { Melanargia galathea } \\
\text { Colias hyale/alfacariensis } \\
\text { Everes argiades } \\
\text { Plebeius argus } \\
\text { Leptidea sinapis/juvernica } \\
\text { Pieris rapae } \\
\text { Polyommatus icarus } \\
\text { Coenonympha pamphilus } \\
\text { Aphantopus hyperantus }\end{array}$ \\
\hline Forest & $\begin{array}{l}20.2 \pm 7.6 \\
\text { Carpinus betulus } \\
\text { Anemone nemorosa } \\
\text { Galium odoratum } \\
\text { Fagus sylvatica } \\
\text { Viola reichenbachiana } \\
\text { Quercus petrea } \\
\text { Dentaria bulbifera } \\
\text { Astrantia major } \\
\text { Stellaria holostea } \\
\text { Helleborus purpurascens }\end{array}$ & $\begin{array}{l}15.0 \pm 2.6 \\
\text { Erithacus rubecula } \\
\text { Fringilla coelebs } \\
\text { Parus major } \\
\text { Turdus merula } \\
\text { Ficedula albicollis } \\
\text { Sturnus vulgaris } \\
\text { Sylvia atricapilla } \\
\text { Phylloscopus collybita } \\
\text { Certhia familiaris } \\
\text { Parus palustris }\end{array}$ & $\begin{array}{l}2.5 \pm 0.71 \\
\text { Maniola jurtina } \\
\text { Argynnis paphia } \\
\text { Inachis io } \\
\text { Pararge aegeria }\end{array}$ \\
\hline
\end{tabular}

The most common species for each land cover type are also shown

method. There were positive correlations between the site-level richness of plants and butterflies (Pearson correlation $\mathrm{r}=0.42$, $\mathrm{df}=24, P<0.05$; cartwheel approach $\mathrm{r}=0.71$, $\mathrm{df}=14, P<0.05)$, but no significant correlations between butterflies and birds $(\mathrm{r}=$ -0.02 , df $=24, P=0.91$ ), and plants and birds (Pearson correlation $\mathrm{r}=-0.004$, $\mathrm{df}=33, P=0.98$; cartwheel approach $\mathrm{r}=-0.39$, $\mathrm{df}=17, P=0.1$ ).

Mean observed species richness per site was 46.9 for plants; 17.7 for butterflies and 9.6 for birds. Observed species richness correlated highly with estimated true species richness from the hierarchical community models (plants $\mathrm{r}=0.83$, df $=17, P<0.001$; birds $\mathrm{r}=0.99$, df $=33, P<0.001$; butterflies $\mathrm{r}=0.99$, $\mathrm{df}=24, P<0.001)$. However, the absolute values of estimated mean richness per site were unrealistically high for plants and butterflies: Plants (mean; credible interval (2.5-97.5 \%): 92.6 (81.9-106.6); Butterflies: 60 (47.5-73.6); Birds: 9.4 (6.7-13.3). Hence, we continued all subsequent analyses using observed species richness. The average detection probabilities were estimated to be 0.25 for birds $( \pm 0.15 \mathrm{SD}), 0.17$ for plants $( \pm 0.12)$ and 0.16 for butterflies $( \pm 0.17)$. 
Correlations between species richness from reduced survey effort and results from the full survey effort showed an overall pattern of asymptotic increase with increasing survey effort, especially for plants (Fig. 2). For species turnover and composition, we also found consistently high correlations between estimates from reduced survey effort and full survey effort. For example, when considering seven plant plots per site, three repeats for birds, and three repeats for butterflies, the mean correlations with estimates for the full dataset were $>0.9$, for species richness, turnover and composition (Fig. 2).

Power analysis with simulated data showed an exponential decrease of the minimum detectable effect with increasing sample size. The marginal increase in statistical power per additional survey site was lower when the number of sites was already high (Fig. 3). Minimum detectable effects were smallest for birds ( 1 species for 100 survey sites) and larger for butterflies and plants (approximately 3 species for 100 survey sites).

\section{Discussion}

Given the fast changes happening in human-dominated landscapes, ecologists need to use efficient survey protocols to be able to detect effects on wildlife. Field research projects face logistical, time and monetary constraints (Tyre et al. 2003), which inherently limit the affordable survey intensity. Dense sampling schemes-such as those that use survey protocols which aim to cover at least three percent of the area of a landscape with at least five repeats (Bried et al. 2011) — are rarely feasible. Typically, only small portions of the landscape can be surveyed (Stohlgren et al. 1997). A common approach therefore is to rely on a stratified random sampling design and then extrapolate data across the landscape (Stohlgren et al. 1997; Rosenstock et al. 2002).

Here, we present a protocol to assess the effects of survey effort on the detection of biodiversity patterns based on a case study. We show that for our data survey efforts per site could be moderately reduced, because the corresponding increase in bias was relatively small and relative biodiversity patterns remained stable. Such a reduction, however, needs to happen in a sensible and balanced way in order to assure sufficient statistical power to detect environmental effects on species richness. Also, this conclusion is based on the assumption that detection probability does not vary spatially.

Overall, our findings are broadly consistent with a range of previous works from different systems. For example, Stohlgren et al. (1997) tested reducing a larger set of plant sample replicates in different vegetation communities in the Rocky Mountains and found that already ten quadrats of one square meter per sampling unit provided sufficient information in order to detect fine-scale patterns of plant diversity. Similarly, other studies showed that in Australia and California, most animal species that were surveyed could be detected even if survey effort within a given sampling protocol was reduced to three repeat surveys (Pellet 2008; Field et al. 2005). Based on an assessment of birds, amphibians and invertebrates in Australia, Tyre et al. (2003) further suggested that with current survey methods, sampling from 100 sites and pooling data over three repeats yielded accurate results. This, too, is consistent with our findings - using 100 or more sites led to minimum detectable effects of changes in species richness in response to heterogeneity of three species for plants and butterflies, and one species for birds. Due to the coherences with findings from other studies, we assume our sampling protocol for landscape-scale surveys is applicable to other study systems as well.

Our results suggest that it can be reasonable to reduce survey effort per site when aiming at broad patterns of biodiversity and when the detectability of investigated taxa is 

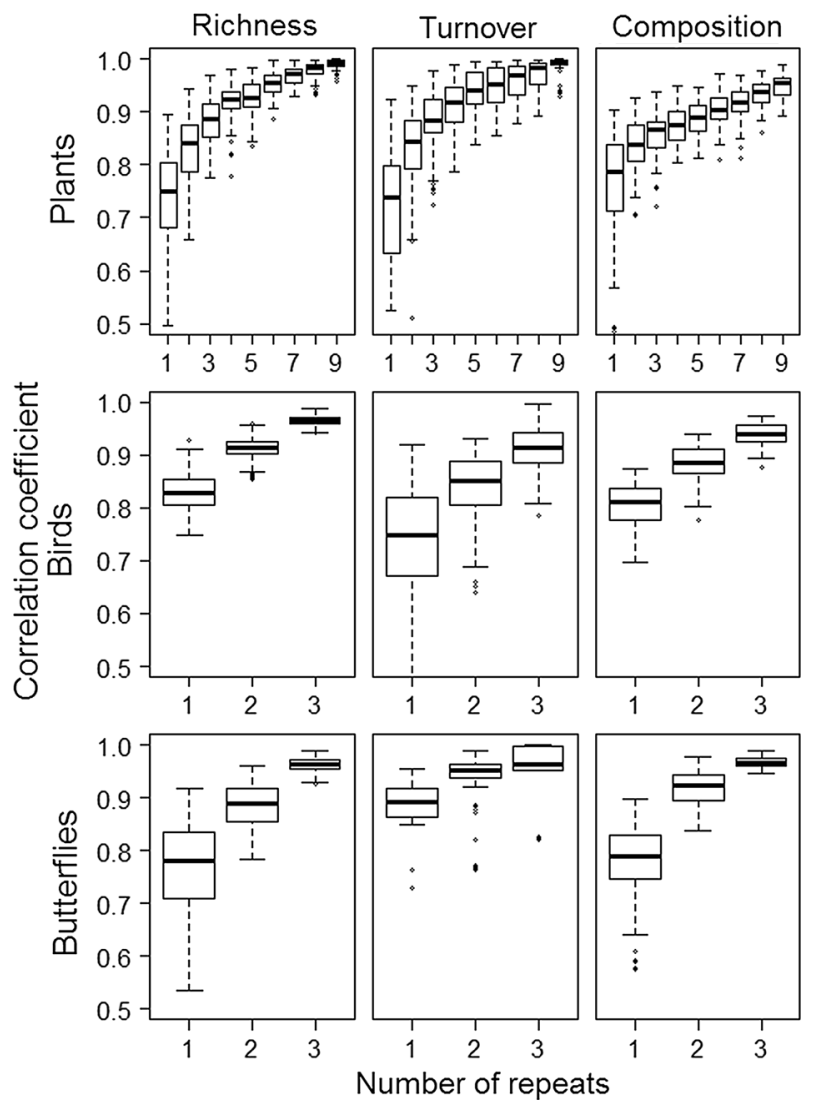

Fig. 2 Correlations between data from reduced survey effort ( 1 to 9 plots for plants; 1 to 3 repeats for birds and butterflies) and the maximum survey effort (10 plots for plants; 4 repeats for birds and butterflies). Reduced survey effort was simulated by randomly sub-setting the full data set 1,000 times for each level of data reduction

high. Moreover, even a low survey effort per site can yield high statistical power provided that the survey effort per site is balanced in a meaningful way with the number of sites surveyed. A key advantage of using many sites is that data then is much more likely to be representative of the study area as a whole, which is valid at least for occurrence patterns of organisms with relatively high abundance and detectability. Abundance greatly influences detectability, and both factors determine whether a species is actually recorded (Royle and Nichols 2003). Rare species and species with a low detectability are highly susceptible to false absences compared to common species or ones with a high detectability, which can lead to an underestimation of their distribution (MacKenzie and Royle 2005; LahozMonfort et al. 2013). Therefore, higher levels of survey effort are often recommended for rare species (e.g. Bried and Pellet 2012). In summary, we demonstrated a useful sampling protocol for assessing broad diversity patterns of relatively abundant species in response to environmental gradients (Vellend et al. 2008). However, we caution that our method may be of limited use for rare or cryptic species. Eventually, the required survey effort depends on the study area and the investigated species (Bried et al. 2012). With our case study, we 


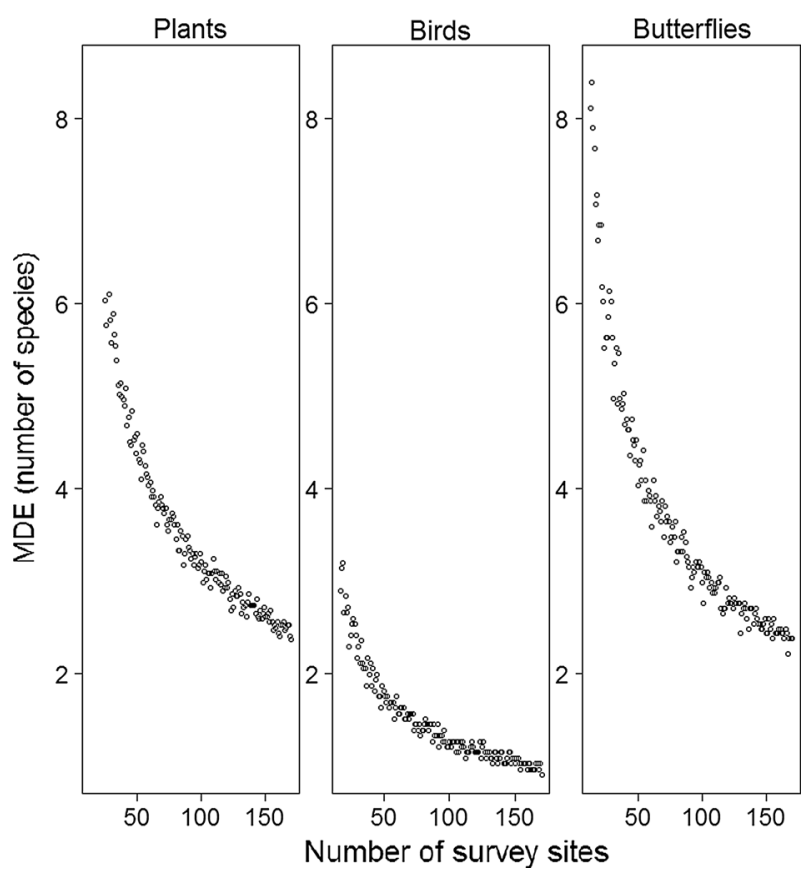

Fig. 3 Power analysis with simulated data. Minimum detectable effect (MDE) is plotted as a function of the number of survey sites. MDE was defined as the absolute change in species richness along the observed heterogeneity gradient in arable fields that could be detected in a linear model with given sample size

provide an example how to allocate project resources meaningfully to obtain a high statistical power.

\section{Conclusion}

Developing field survey protocols is a challenging task for ecologists and demands thorough consideration of both theoretical and practical issues. Our results suggest that in Southern Transylvania, at least three temporal replicates on at least 100 study sites appeared to be sufficient to study landscape effects on diversity patterns of birds and butterflies following our sampling methods. To model plant diversity patterns, a combination of seven one square meter plots per one hectare site at approximately 100 sites appeared to be sufficient.

Before implementing landscape-scale surveys, we recommend ecologists conduct pilot studies for several reasons: (1) to trial and customize different techniques and sampling schemes; (2) to identify what is the most efficient use of available resources; and (3) to estimate the statistical power of plausible alternative designs. Our findings suggest that under certain conditions, relative patterns of biodiversity can remain relatively stable, when survey effort is moderately reduced. This in turn, can help to allocate resources to sampling more sites and to more representatively survey large areas. The general procedure presented in this paper is transferrable to other study systems and may be used as a guideline to help develop reasonable survey designs. 
Acknowledgments The study was funded through a Sofja Kovalevskaja Award by the Alexander von Humboldt Foundation to Joern Fischer, financed by the German Ministry for Research and Education. We are grateful for help with fieldwork to Kimberlie Rawlings, Pascal Fust and Doreen Hoffmann. Levente Székely and Kuno Martini provided helpful information on local species. Izabela Hartel and Caroline Fernolend provided valuable logistical support. We thank Elise Zipkin for providing R and WinBUGS code and Marc Kéry for useful comments on the hierarchical models. We appreciate numerous discussions with Tibor Hartel. Thanks to Ine Dorresteijn and two anonymous reviewers for helpful comments on the manuscript.

Open Access This article is distributed under the terms of the Creative Commons Attribution License which permits any use, distribution, and reproduction in any medium, provided the original author(s) and the source are credited.

\section{References}

Akeroyd JR (2006) The historic countryside of the Saxon Villages of Southern Transylvania Fundatia Adept, Saschiz, Romania

Akeroyd JR, Page N (2011) Conservation of high nature value (HNV) grassland in a farmed landscape in Transylvania, Romania. Contrib Bot XLVI:57-71

Anderson MJ, Crist TO, Chase JM, Vellend M, Inouye BD, Freestone AL, Sanders NJ, Cornell HV, Comita LS, Davies KF, Harrison SP, Kraft NJB, Stegen JC, Swenson NG (2011) Navigating the multiple meanings of beta diversity: a roadmap for the practicing ecologist. Ecol Lett 14(1):19-28

Baasch A, Tischew S, Bruelheide H (2010) How much effort is required for proper monitoring? Assessing the effects of different survey scenarios in a dry acidic grassland. J Veg Sci 21(5):876-887

Bailey LL, Hines JE, Nichols JD, MacKenzie DI (2007) Sampling design trade-offs in occupancy studies with imperfect detection: examples and software. Ecol Appl 17(1):281-290

Baur B, Cremene C, Groza G, Rakosy L, Schileyko AA, Baur A, Stoll P, Erhardt A (2006) Effects of abandonment of subalpine hay meadows on plant and invertebrate diversity in Transylvania, Romania. Biol Conserv 132(2):261-273

Benton TG, Vickery JA, Wilson JD (2003) Farmland biodiversity: is habitat heterogeneity the key? Trends Ecol Evol 18(4):182-188

Bibby CJ (2000) Bird census techniques, 2nd edn. Academic Press, London

Bolker BM (2008) Ecological models and data in R. Princeton University Press, Princeton

Bouma J, Varallyay G, Batjes NH (1998) Principal land use changes anticipated in Europe. Agric Ecosyst Environ 67(2-3): 103-119

Bried JT, Pellet J (2012) Optimal design of butterfly occupancy surveys and testing if occupancy converts to abundance for sparse populations. J Insect Conserv 16(4):489-499

Bried JT, Langwig KE, Dewan AA, Gifford NA (2011) Habitat associations and survey effort for shrubland birds in an urban pine barrens preserve. Landsc Urban Plan 99(3-4):218-225

Bried JT, Hager BJ, Hunt PD, Fox JN, Jensen HJ, Vowels KM (2012) Bias of reduced-effort community surveys for adult Odonata of lentic waters. Insect Conserv Divers 5(3):213-222. doi:10.1111/j.17524598.2011.00156.x

Dorazio RM, Royle JA (2005) Estimating size and composition of biological communities by modeling the occurrence of species. J Am Stat Assoc 100(470):389-398

Dorazio RM, Royle JA, Söderström B, Glimskär A (2006) Estimating species richness and accumulation by modeling species occurrence and detectability. Ecology 87(4):842-854

Dover JW, Warren MS, Shreeve TG (2011) 2010 and beyond for Lepidoptera. J Insect Conserv 15(1-2):1-3

Field SA, Tyre AJ, Possingham HP (2005) Optimizing allocation of monitoring effort under economic and observational constraints. J Wildlife Manage 69(2):473-482

Fischer J, Hartel T, Kuemmerle T (2012) Conservation policy in traditional farming landscapes. Conserv Lett 5:167-175

Gaston KJ (2000) Global patterns in biodiversity. Nature 405(6783):220-227

Guillera-Arroita G, Lahoz-Monfort JJ (2012) Designing studies to detect differences in species occupancy: power analysis under imperfect detection. Methods Ecol Evol 3(5):860-869

Guillera-Arroita G, Ridout MS, Morgan BJT (2010) Design of occupancy studies with imperfect detection. Methods Ecol Evol 1(2):131-139

Guillera-Arroita G, Morgan BJ, Ridout MS, Linkie M (2011) Species occupancy modeling for detection data collected along a transect. J Agric Biol Environ Stat 16(3):301-317 
Kéry M, Royle JA (2009) Inference about species richness and community structure using species-specific occupancy models in the National Swiss Breeding Bird Survey MHB. In: Thomson DL, Cooch EG, Conroy MJ (eds) Modeling demographic processes in marked populations, environmental and ecological statistics 3. Springer, New York, pp 639-656

Kéry M, Schaub M (2012) Bayesian population analysis using WinBUGS a hierarchical perspective, 1st edn. Academic Press, Boston

Kessler M, Abrahamczyk S, Bos M, Buchori D, Putra DD, Gradstein SR, Hohn P, Kluge J, Orend F, Pitopang R, Saleh S, Schulze CH, Sporn SG, Steffan-Dewenter I, Tjitrosoedirdjo S, Tscharntke T (2009) Alpha and beta diversity of plants and animals along a tropical land-use gradient. Ecol Appl 19(8):2142-2156

Klimek S, Richter A, Hofmann M, Isselstein J (2007) Plant species richness and composition in managed grasslands: the relative importance of field management and environmental factors. Biol Conserv 134(4):559-570

Kuemmerle T, Muller D, Griffiths P, Rusu M (2008) Land use change in Southern Romania after the collapse of socialism. Reg Environ Chang 9(1):1-12. doi:10.1007/s10113-008-0050-Z

Lafranchis T (2004) Butterflies of Europe. Diatheo, Paris

Lahoz-Monfort JJ, Guillera-Arroita G, Wintle BA (2013) Imperfect detection impacts the performance of species distribution models. Glob Ecol Biogeogr 23(4):504-515. doi:10.1111/geb.12138

Legg CJ, Nagy L (2006) Why most conservation monitoring is, but need not be, a waste of time. J Environ Manage 78(2):194-199

Lobo JM, Jimenez-Valverde A, Hortal J (2010) The uncertain nature of absences and their importance in species distribution modelling. Ecography 33(1):103-114

MacKenzie DI, Royle JA (2005) Designing occupancy studies: general advice and allocating survey effort. J Appl Ecol 42(6):1105-1114

MacKenzie DI, Nichols JD, Lachman GB, Droege S, Royle JA, Langtimm CA (2002) Estimating site occupancy rates when detection probabilities are less than one. Ecology 83(8):2248-2255. doi:10. 2307/3072056

Mouysset L, Doyen L, Jiguet F (2012) Different policy scenarios to promote various targets of biodiversity. Ecol Ind 14(1):209-221

Page N, Bălan A, Popa SHR, Rákosy L, Sutcliffe L (2012) România/Romania. In: Oppermann R, Beaufoy GJ (eds) High nature value farming in Europe. Verlag Regionalkultur, Ubstadt-Weiher, pp 346-358

Pellet J (2008) Seasonal variation in detectability of butterflies surveyed with Pollard walks. J Insect Conserv 12(2):155-162

Peres-Neto PR, Jackson DA (2001) How well do multivariate data sets match? The advantages of a Procrustean superimposition approach over the Mantel test. Oecologia 129(2):169-178

Pollard E, Yates TJ (1993) Monitoring butterflies for ecology and conservation : the British butterfly monitoring scheme, vol 1., Conservation biology seriesChapman \& Hall, London

Rakosy L (2005) U.E- şi legislaţie pentru protecţia lepidopterelor din România. Buletin de Informare Entomologică 16:89-96

Rands MRW, Adams WM, Bennun L, Butchart SHM, Clements A, Coomes D, Entwistle A, Hodge I, Kapos V, Scharlemann JPW, Sutherland WJ, Vira B (2010) Biodiversity conservation: challenges beyond 2010. Science 329(5997):1298-1303

Reed MS, Buenemann M, Atlhopheng J, Akhtar-Schuster M, Bachmann F, Bastin G, Bigas H, Chanda R, Dougill AJ, Essahli W, Evely AC, Fleskens L, Geeson N, Glass JH, Hessel R, Holden J, Ioris AAR, Kruger B, Liniger HP, Mphinyane W, Nainggolan D, Perkins J, Raymond CM, Ritsema CJ, Schwilch G, Sebego R, Seely M, Stringer LC, Thomas R, Twomlow S, Verzandvoort S (2011) Cross-scale monitoring and assessment of land degradation and sustainable land management: a methodological framework for knowledge management. Land Degrad Dev 22(2):261-271

Reynolds JH, Thompson WL, Russell B (2011) Planning for success: identifying effective and efficient survey designs for monitoring. Biol Conserv 144(5):1278-1284

Rosenstock SS, Anderson DR, Giesen KM, Leukering T, Carter MF (2002) Landbird counting techniques: current practices and an alternative. Auk 119(1):46-53

Royle JA, Nichols JD (2003) Estimating abundance from repeated presence-absence data or point counts. Ecology 84(3):777-790

Sala OE, Chapin FS, Armesto JJ, Berlow E, Bloomfield J, Dirzo R, Huber-Sanwald E, Huenneke LF, Jackson RB, Kinzig A, Leemans R, Lodge DM, Mooney HA, Oesterheld M, Poff NL, Sykes MT, Walker BH, Walker M, Wall DH (2000) Biodiversity-global biodiversity scenarios for the year 2100. Science 287(5459):1770-1774

Sewell D, Guillera-Arroita G, Griffiths RA, Beebee TJ (2012) When is a species declining? Optimizing survey effort to detect population changes in reptiles. PLoS ONE 7(8):e43387 
Stauffer HB, Ralph CJ, Miller SL (2002) Incorporating detection uncertainty into presence-absence surveys for marbled murrelet. In: Scott JM, Heglund PJ, Morrison ML et al. (eds) Predicting species occurrences. Issues of Accuracy and Scale. Island Press, Washington D.C., pp 357-368

Stoate C, Baldi A, Beja P, Boatman ND, Herzon I, van Doorn A, de Snoo GR, Rakosy L, Ramwell C (2009) Ecological impacts of early 21st century agricultural change in Europe-a review. J Environ Manage 91(1):22-46

Stohlgren TJ, Chong GW, Kalkhan MA, Schell LD (1997) Rapid assessment of plant diversity patterns: a methodology for landscapes. Environ Monit Assess 48(1):25-43

Suarez-Seoane S, Osborne PE, Baudry J (2002) Responses of birds of different biogeographic origins and habitat requirements to agricultural land abandonment in northern Spain. Biol Conserv 105(3):333-344

Ter Braak CJF, Prentice IC (1988) A theory of gradient analysis. Adv Ecol Res 18:271-317

Tscharntke T, Klein AM, Kruess A, Steffan-Dewenter I, Thies C (2005) Landscape perspectives on agricultural intensification and biodiversity-ecosystem service management. Ecol Lett 8(8):857-874

Tshikolovets VV (2003) Butterflies of Eastern Europe, Urals and Caucasus. An illustrated guide. Vadim V Tshikolovets, Kiev

Tylianakis JM, Klein A-M, Tscharntke T (2005) Spatiotemporal variation in the diversity of Hymenoptera across a tropical habitat gradient. Ecology 86(12):3296-3302

Tyre AJ, Tenhumberg B, Field SA, Niejalke D, Parris K, Possingham HP (2003) Improving precision and reducing bias in biological surveys: estimating false-negative error rates. Ecol Appl 13(6):1790-1801

Vellend M, Lilley PL, Starzomski BM (2008) Using subsets of species in biodiversity surveys. J Appl Ecol 45(1):161-169

Verhulst J, Baldi A, Kleijn D (2004) Relationship between land-use intensity and species richness and abundance of birds in Hungary. Agric Ecosyst Environ 104(3):465-473

Whittaker RH (1960) Vegetation of the Siskiyou mountains, Oregon and California. Ecol Monogr 30(2):279-338

Yoccoz NG, Nichols JD, Boulinier T (2001) Monitoring of biological diversity in space and time. Trends Ecol Evol 16(8):446-453

Zipkin EF, Dewan A, Royle JA (2009) Impacts of forest fragmentation on species richness: a hierarchical approach to community modelling. J Appl Ecol 46(4):815-822 